\title{
Recent progress in the design and clinical development of electronic-nose technologies
}

This article was published in the following Dove Press journal:

Nanobiosensors in Disease Diagnosis

22 January 2016

Number of times this article has been viewed

\section{Alphus D Wilson}

Forest Insect and Disease Research (FIDR), Southern Hardwoods Laboratory, Center for Bottomland Hardwoods Research, Southern Research Station, USDA Forest Service, Stoneville, MS, USA
Correspondence: Alphus D Wilson Southern Hardwoods Laboratory, Center for Bottomland Hardwoods Research, Southern Research Station, USDA Forest Service, PO Box 227, Stoneville, MS 38776-0227, USA

Tel +l 6626863180

Fax + I 6626863195

Email dwilson02@fs.fed.us
Abstract: Electronic-nose (e-nose) devices are instruments designed to detect and discriminate between precise complex gaseous mixtures of volatile organic compounds derived from specific organic sources, such as clinical test samples from patients, based on electronic aroma signature patterns (distinct digital sensor responses) resulting from the combined outputs of a multisensor array. E-nose tools allow the identification of complex gaseous samples at relatively low costs, making them useful in a diverse range of clinical situations, particularly for assessments of a patients' metabolic (physiological) health and for diagnostic applications. The acquisition and analysis of e-nose clinical "breathprints" or "smellprints", taken from patients' exhaled air, allow for the potential detection of a wide range of human ailments due to abnormal metabolic activities, disorders, and diseases that may be present in the lungs, other organs, and various compartments of the human body. E-nose instruments have shown strong capabilities for detecting inflammatory lung diseases, various types of cancers, patients' exposure to toxins and harmful drugs, organ failures, and many other abnormal human conditions. The increasing trend of medical procedures to move toward the use of noninvasive diagnostic methods, such as breath analysis of complex gases and metabolic biomarkers using e-nose devices, is likely to continue because these methods are quicker, more efficient, and cause less stress, anxiety, and pain to patients. The need for standardization of e-nose analysis methods for use in clinical applications will be resolved with new research, eventually allowing the use of portable e-nose devices in clinical practice to become routine and accepted as the preferred tools of choice by physicians for many clinical tasks. This review provides a brief summary of recent progress in the development of e-nose applications for clinical examinations, general medical practice, and for other branches of medical science and research.

Keywords: breath analysis, electronic aroma detection, e-nose, point-of-care diagnostic testing, volatile organic compounds

\section{Introduction}

Conventional methods and monitoring technologies utilized for clinical diagnostics and related medical research have focused on the analysis of volatile organic compounds (VOCs) emitted from patient's samples, such as from their exhaled or expired breath (EB), urine, blood, serum, sputum, and feces. ${ }^{1}$ Chemical analysis technologies and methodologies, including selected ion flow tube mass spectrometry, ${ }^{2}$ proton transfer reaction mass spectrometry, ${ }^{3}$ and gas chromatography-mass spectrometry ${ }^{4}$ with thermal desorption or solid-phase microextraction have been widely used in clinical diagnostics, but these methods are expensive, time-consuming, and often result in delays in diagnoses and treatments for diseases. Selected ion flow tube mass spectrometry and proton transfer reaction mass spectrometry analytical techniques were developed 
for real-time online detection and quantification of trace gases derived from breath air, urine, and fecal samples, and for cell culture studies. ${ }^{5}$ Unfortunately, the identification of specific chemicals alone, such as individual metabolic biomarkers present in complex gaseous (headspace) test samples from patients, does not often lead to easy diagnoses. The aroma signature of the entire mixture of VOCs, found in the headspace from patients' test samples, often is more informative and indicative of abnormal metabolic conditions within the body that may indicate the presence of disease or other ailments. By this approach, the detection of specific mixtures of known disease-related biomarkers present in sample headspace is significantly more reliable for diagnostic determinations.

The electronic nose (e-nose) is a relatively new gasdetection technology adapted for use as a medical tool for various clinical applications. ${ }^{6,7}$ E-nose instruments useful for clinical applications generally are small, portable devices that can detect and discriminate between precise complex VOC mixtures of gas-analyte samples from patients with good precision and reasonable accuracy for diagnosing diseases. These devices work by detecting abnormal VOCs in the exhaled air of diseased patients that are different from VOCs released by healthy individuals. In spite of the advantages provided by e-nose instruments, disease and health diagnostics based on VOCs profiling still has not yet been widely used in clinical practice, but significant progress is currently underway as evident by the numerous examples of e-nose clinical research trials presented in this review.

The basic e-nose system consists of a multisensor array, transducer to convert the sensor analog responses to digital values, software to control data recordings, pattern recognition through an artificial neural network (ANN), statistical analyses, gas sample collection chamber containing VOC-filtered ambient air (serving as a baseline), and sampling container that holds the headspace from the sample analyte..$^{8,9}$ The gas-collecting bottles or bags are connected to the e-nose and sensor array through a purge inlet (baseline air) and a sample inlet (sample air) using a syringe or fixed connector. Specialized e-nose software allows adjustments of setting parameters for sample gas introduction, data acquisition, and analysis processing. E-nose instruments useful for clinical applications are handheld, portable devices that provide immediate (real-time) rapid results, are noninvasive, cost-effective, and easy to operate compared with complicated, expensive, and time-intensive chemicalanalysis instruments and methods currently available for analyzing clinical test samples. These versatile and relatively simple machines provide characteristics and capabilities that are more useful for clinical applications in routine patient examinations.

The most common types of e-nose devices available for clinical practice include surface acoustic wave (SAW), quartz crystal microbalance (QCM), metal oxide semiconductors (MOS), conducting polymers (CP), and carbon nanofiber (CNF) that are representative of electronic aroma detection technologies. ${ }^{10,11}$ Design details of sensor characteristics such as sensitivity, VOC-sensitive components, detection mechanisms, response times, advantages, and disadvantages of each e-nose type are summarized in Table 1. Sensors of CNF, CP, and MOS e-nose types operate through the detection of electrical resistance changes that occur when VOCs are adsorbed onto to the surfaces of individual sensors within the sensor array. By contrast, SAW and QCM sensors function by detecting the mass of VOCs adsorbed onto the sensor surface through shifts in sensor vibration frequency. Generally, QCM and SAW sensors are much more sensitive and exhibit similar or faster response times than CP, CNF, and MOS sensors. Optical sensors have high VOC sensitivity, but are expensive, have high operation costs, and low portability (due to the difficulty of miniaturization), currently making them inadequate for clinical use. The utility of individual e-nose technologies largely depends on the particular medical application, chemical classes of target analytes, instrument miniaturization potential, manufacturing costs, analysis time, and ease of operation. ${ }^{6-8}$

This review focuses on the current status of recent developments in e-nose technologies for numerous applications in clinical practice including the potential for providing many new noninvasive diagnostic applications for the detection of specific human diseases associated with various organ systems and compartments of the body. Specific examples demonstrate recent e-nose developments for point-of-care testing (POCT) and summarize the many ways in which these technologies are beginning to change clinical procedures to reduce time-consuming and expensive laboratory tests and improve the efficiency of patient care and treatments.

\section{Range of recent e-nose applications}

The versatility of e-nose devices in measuring, characterizing, and discriminating between complex gas mixtures of VOCs derived from clinical samples makes these ideal instruments for noninvasive, rapid, real-time diagnoses of diseases in the human body. ${ }^{6,11,35}$ E-noses are relatively low cost and mobile (portable) electronic instruments that have rapid response and recovery times, good sensitivity and 


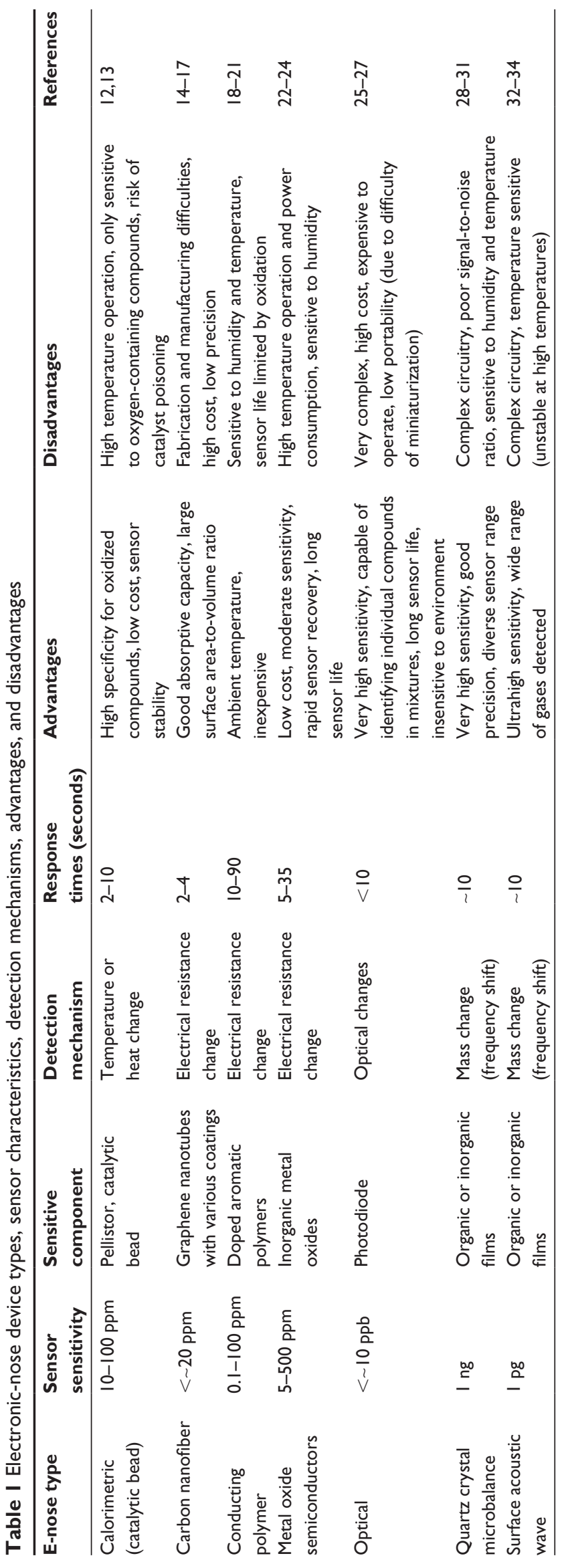

precision, and are effective particularly when applicationspecific specialized instrument configurations and reference databases are utilized for certain types of disease diagnoses. ${ }^{6,36}$ The wide range of e-nose designs, using different gas-detection methods and operating principles, offer great potential for a large diversity of detection capabilities for analyzing various sample types taken from patients for numerous clinical applications.

The diversity of recently developed applications of e-nose instruments in clinical medicine includes the detection of physiological abnormalities and disorders, patient drug use, exposures to toxic chemicals and hazardous gases, organ failures or dysfunctions, and metabolic conditions as well as various types of diseases in different parts of the body (Table 2). The largest and most significant e-nose application area for clinical practice has been in disease diagnosis. There has been recent progress in the detection and diagnosis of human diseases using different types of e-nose technologies, particularly for cancer detection in various organs and tissues of the breast, colon, lungs, ovaries, and prostate. Another significant area of progress has been in the detection of bacterial and fungal pathogens in the blood, lungs, skin, upper airways, and urinary tract. Continued improvements in e-nose diagnoses of inflammatory lung diseases such as asthma, cystic fibrosis (CF), and chronic obstructive pulmonary disease have been achieved with CP, MOS, and QCM-type e-noses. ${ }^{43}$ The mosquito-borne infectious disease (malaria) caused by the parasitic protozoan of the genus Plasmodium, particularly $P$. falciparum, was recently detected using an experimental CNF e-nose (biosensor), based on P. falciparum-specific histidinerich protein-2 antigen detection using $\mathrm{CNF}$ forests grown on glass microballoons, coated with secondary antibodies specific to $P$. falciparum-specific histidine-rich protein-2. ${ }^{38}$ This CNF method employed a sandwich immunoassay protocol that was capable of detecting the malaria pathogen at minute concentrations, levels as low as $0.025 \mathrm{ng} / \mathrm{mL}$ concentration in phosphate-buffered saline using a visual signal within only 1 minute of test duration. The lower limit of $0.01 \mathrm{~g} / \mathrm{mL}$ was obtained by measuring the electrical resistivity of the capture zone.

Recent advances in clinical e-nose applications have also been achieved in the detection of patients' drug use, exposure to hazardous gases and toxins, organ failure, and physiological abnormalities. MOS-type e-nose sensors have been used for many of these applications for detections of abnormal gases released from the lungs (in breath), mouth cavity, skin, and headspace VOCs from various body fluids. Specialized atypical e-nose sensor types such as field-effect 
Table 2 Recent applications of electronic-nose devices in clinical practice

\begin{tabular}{|c|c|c|c|c|c|}
\hline Applications & Organ system & Detection & E-nose model system & $\begin{array}{l}\text { Sensor type and } \\
\text { number }\end{array}$ & References \\
\hline \multirow[t]{13}{*}{ Disease diagnosis } & Blood & Pathogen (Salmonella) & DR-ADF $\mathrm{SiO}_{2}-\mathrm{TiO}_{2}$ biosensor & MOS-BS & 37 \\
\hline & Blood & Malaria & Experimental CNF on NMBs & CNF-BS & 38 \\
\hline & Breast & Cancer & BreathLink (GC + SAW) & SAW I & 39 \\
\hline & Colon & Cancer & Cyranose 320 & CP 32 & 40 \\
\hline & Foot & Microbial infections & Cyranose 320 & CP 32 & 41 \\
\hline & Lung & Cancer & $\begin{array}{l}\text { Many types: gold } \\
\text { nanoparticles, CP, MOS, SAW }\end{array}$ & Various & 42 \\
\hline & Lung & Asthma, CF, COPD, TB & Bloodhound II4 & CP 14 & 43 \\
\hline & & & Cyranose 320 & CP 32 & \\
\hline & & & MOSES II e-nose & MOS 8, QMB 8 & \\
\hline & Ovaries & Cancer & $\begin{array}{l}\mathrm{SnO}_{2}, \mathrm{TiO}_{2} \text { Figaro } \\
\mathrm{TGS} 2600 \text {-series }\end{array}$ & MOS 16 & 44 \\
\hline & Prostate & Cancer & ChemPro I00i & IMS I & 45 \\
\hline & Upper airway & OSAS & Cyranose 320 & CP 32 & 46 \\
\hline & Urinary & Pathogens & IMS Cell-e-nose & IMS 8, MOS 6 & 47 \\
\hline \multirow[t]{2}{*}{ Drug use } & Mouth & Alcohol (ethanol) & $\begin{array}{l}\text { Experimental } \mathrm{SnO}_{2} / \mathrm{ZnO} \\
\text { core-shell nanorods }\end{array}$ & MOS & 48 \\
\hline & Skin & Marijuana (Cannabis) & Experimental $\mathrm{SnO}_{2}$ & MOS 3 & 49 \\
\hline $\begin{array}{l}\text { Hazardous gas } \\
\text { exposure }\end{array}$ & Lungs & $\mathrm{CO}, \mathrm{NO}_{2}, \mathrm{NH}_{3}, \mathrm{SO}_{2}$ & $\mathrm{In}_{2} \mathrm{O}_{3}^{-}, \mathrm{SnO}_{2}^{-}, \mathrm{CNT}$-based FETs & FET & 50 \\
\hline Organ failure & Kidney & Ammonia breath analysis & TGS 2602 & MOS I & 51 \\
\hline Patient ID & Body & Human odors & Experimental TGS (Tagushi) e-nose & MOS 5 & 52 \\
\hline \multirow[t]{3}{*}{ Physiological } & Body fluids & Health parameters & CardioMEMS, others & MEMs & 53 \\
\hline & & Antioxidant capacity & TGS 2602 EC biosensor & $\mathrm{ECB}$ & 54 \\
\hline & & Urea buildup & Silica-gel $\mathrm{SiO}_{2} \mathrm{NPs}$ biosensor & SG-BS & 55 \\
\hline Toxin exposure & Body fluids & Mercury poisoning & Experimental ISE & EC & 56 \\
\hline
\end{tabular}

Abbreviations: BS, biosensor (experimental technology); CF, cystic fibrosis; CNF, carbon nanofiber; CNT, carbon nanotube; COPD, chronic obstructive pulmonary disease; $\mathrm{CP}$, conducting polymer; EC, electrochemical; ECB, electrochemical biosensor; FETs, field-effect transistors; GC, gas chromatography; IMS, ion mobility spectrometry; ISEs, ionselective electrodes; MEMs, microelectromechanical systems; MOS, metal oxide semiconductor; NMB, carbon nanofiber forests grown on glass microballoons; OSAS, obstructive sleep apnea syndrome; QMB, quartz microbalance; SAW, surface acoustic wave; SG-BS, silica gel biosensor; TB, tuberculosis; ID, identification; e-nose, electronic-nose.

transistors, microelectromechanical systems, ion-selective electrodes, silica-gel nanospheres, and electrochemicals were utilized for these clinical gas-detection diagnostic applications mostly from the analysis of VOCs and toxic metals present in body fluids.

\section{Noninvasive disease diagnoses}

The early detection of human diseases by noninvasive methods increasingly is becoming a key primary technological goal for many leading clinics and hospitals worldwide. The reasoning behind this policy shift has been due to the repeatedly devastating results and consequences of late diagnoses. For diseases such as cancer that have already reached life-threatening stages, the prognosis is often poor. The benefits of early detection, allowing early treatments of diseases, are obvious as prognoses are greatly improved. Many patients often avoid regular prophylactic checkups and early disease screenings because many current methods (eg, colonoscopies, X-ray mammographies, tissue biopsies, uterine dilation, and curettage) still involve invasive, painful, or expensive procedures. ${ }^{35}$ Many of these methods present risks of significant negative side effects and often are sufficiently painful to discourage patients from participating in preemptive, prophylactic disease-screening procedures. Hence, there is an increasing urgent need for the development of new efficient, rapid, and relatively cheap diagnostic tools, particularly those which reliably detect diseases at early stages of development. For field applications, such technologies must be cheap, reliable, rugged, and portable, otherwise they may not be available to people living in developing countries.

The need for new, noninvasive diagnostic tools for the reliable early detection of human diseases has led to the discovery of new versatile e-nose methods such as human breath analysis that have provided great promise in facilitating the detection and treatment of a wide range of diseases. Breath analysis is a relatively rapid, noninvasive diagnostic approach that relies on the detection and characterization of abnormal volatile metabolites, referred to as biomarkers (released in EB), which are indicative of specific diseases present in specific compartments of the body. ${ }^{11,35}$ The exhaled breath from individuals contains VOCs that provide important information about the health of the patient. For example, breathprints 
may be used to identify general physiological conditions and processes, either normal or abnormal, occurring within the body. Breathprints are the result of analyses by a series of sensors within the e-nose sensor array that are capable of detecting VOCs through changes in sensor responses to all of the compounds present in the gaseous sample analyte. E-nose instruments are trained to recognize specific breathprints through pattern recognition algorithms that compare the sensor aroma pattern to previously recorded breathprint patterns in reference databases. Data obtained from pattern recognition can be analyzed throughout various statistical methods, including cross-validation, principal component analysis, and discriminant analysis. The composition of VOCs present in the bloodstream and airways provides useful measures of the overall metabolic (physiological) status and health condition of the entire body as well as some indications of the healthful condition of individual organs and other soft-tissue compartments (blood vessels, connective, epithelial, nerves, muscle, and fat tissues) of the body, where many specific diseases are localized. ${ }^{35,57} \mathrm{E}$-nose disease detection, based on analysis of aroma signatures for specific mixtures of VOCs and other biomarker metabolites present in the human breath, is a significant diagnostic advantage of breath analysis due to the capability of identifying a disease and locating the probable presence of the disease within specific tissues or compartments of the body.

Breath is the most obvious gaseous matrix for noninvasive analysis of VOCs generated within the body because abnormal VOCs from diseased tissues travel around the body via the blood and eventually end up in the lungs, cross the alveolar interface, and are released in exhaled breath at specific concentrations that are indicative of physiological states. ${ }^{35,57,58}$ Although trace compounds produced in the oral cavity do not necessarily enter the bloodstream, they appear in exhaled breath. E-nose analysis of VOC concentrations in the breath can provide an indicator of metabolic (physiological) status, allowing a distinction between healthy and diseased states, and also noninvasive and painless detection of diseases in early stages of development.

A summary of research studies by scientists worldwide provides recent examples of efforts to test new potential applications of various e-nose technologies to detect specific human heart and lung diseases through analysis of complex VOCs and biomarkers in the human breath (Table 3). Most of these studies, conducted primarily by researchers at major university hospitals and clinics, have focused on the detection and diagnosis of inflammatory lung diseases, such as acute respiratory distress syndrome (ARDS), asthma, chronic obstructive pulmonary disease, invasive pulmonary aspergillosis (IPA), malignant pleural mesothelioma, and acute or chronic bacterial infections, including pulmonary tuberculosis, upper respiratory tract infections, and ventilatorassociated pneumonia. The majority of these studies tested the efficacy of CP-type e-noses with a 32-sensor array, although a few studies utilized MOS, SAW, and quartz microbalance (QMB)-type e-noses with fewer sensors, or a calorimetric-type e-nose with a 36-sensor array. E-noses with greater numbers of sensors generally provide better discrimination between analyte sample types, but are often more expensive.

Aspergillosis is a fungal disease caused by species of Aspergillus such as A. fumigatus, A. flavus, and A. terreus. Aspergillosis can occur in a variety of organs, both in humans and animals, although the most common infection sites are the lungs and sinuses due to the inhalation of asexual spores (conidia) of the fungus into the airways. Different forms of the disease include IPA, noninvasive aspergillosis, chronic pulmonary aspergillosis, and severe asthma with fungal sensitization. The most common conventional methods for diagnosis of IPA are based on: 1) isolating and culturing the microbe from infected tissue; 2) direct observation of hyphal elements (hyphae) invading tissues (from infected tissue biopsy); 3) chest X-ray computed tomography scan or bronchoscopy showing the presence of one or more lung cavities, scarred lungs, or fungal balls; 4) blood or tissue fluid testing positive for Aspergillus antibodies; and 5) the presence of certain symptoms lasting for more than 3 months, including breathlessness, coughing, fatigue, hemoptysis, and weight loss. ${ }^{82}$

E-nose instruments have been proven to provide reliable and much more rapid diagnoses of IPA due to the detection of abnormal VOCs produced by the disease, as proof of fungal infection, not just by the volatiles produced by the pathogen alone. In a study by Gerritsen et al, ${ }^{83}$ the Cyranose 320 e-nose was used to detect IPA at an early stage through principal component analysis at a sensitivity and specificity of $100 \%$ and $83.3 \%$, respectively. VOC patterns from patients with prolonged chemotherapy-induced neutropenia also could be detected with the e-nose technology. Thus, the high mortality rate of IPA can be significantly reduced through a timely e-nose early diagnosis.

Joensen et a ${ }^{84}$ analyzed breathprints of 64 pediatric patients suffering from $\mathrm{CF}$ using a Cyranose 320 e-nose in order to investigate potential differences compared with samples from 21 patients with primary ciliary dyskinesia and 21 healthy volunteers, with statistical significance 
Table 3 Research studies utilizing electronic-nose instruments to detect human diseases via biomarkers in the human breath

\begin{tabular}{|c|c|c|c|c|c|}
\hline Diseases & Location & $\mathbf{N}$ & Research hospital or clinic location & $\begin{array}{l}\text { Sensor type and } \\
\text { number }\end{array}$ & Reference \\
\hline ARDS-MPM & Lung & 78 & $\begin{array}{l}\text { St Vincent and Prince of Wales Hospital, Sydney, } \\
\text { Australia }\end{array}$ & CP 32 & 59 \\
\hline \multirow[t]{2}{*}{ Asthma } & Lung & 40 & Leiden University MC, Leiden, the Netherlands & CP 32 & 60 \\
\hline & & 51 & Instituto Dermopatico deli' Immacolata, Rome, Italy & QMB 8 & 61 \\
\hline \multirow[t]{3}{*}{ Asthma-COPD } & Lung & 90 & $\begin{array}{l}\text { Academic MC Amsterdam, Haga Teaching Hospital, } \\
\text { The Hague; Albert Schweitzer Hospital, Dordrecht, } \\
\text { the Netherlands }\end{array}$ & CP 32 & 62 \\
\hline & & 100 & $\begin{array}{l}\text { Academic MC Amsterdam, Haga Teaching Hospital, } \\
\text { The Hague; Albert Schweitzer Hospital, Dordrecht, } \\
\text { the Netherlands }\end{array}$ & CP 32 & 63 \\
\hline & & 44 & University of New South Wales, Sydney, Australia & CP 32 & 64 \\
\hline \multirow[t]{5}{*}{ Cancer } & Lung & 62 & C. Forlanini Hospital, Rome, Italy & QMB 8 & 65 \\
\hline & & 135 & Cleveland Clinic, Ohio, USA & CP 32 & 66 \\
\hline & & 143 & Cleveland Clinic, Ohio, USA & CM 36 & 67 \\
\hline & & 92 & C. Forlanini Hospital, Rome, Italy & QMB 8 & 68 \\
\hline & & 229 & Cleveland Clinic, Ohio, USA & CM 36 & 69 \\
\hline COPD & Lung & 43 & Phillips University, Marburg, Germany & CP 32 & 70 \\
\hline COPD-cancer & Lung & 30 & Leiden University MC, Leiden, the Netherlands & $\mathrm{CP} 32$ & 71 \\
\hline Endocarditis (infective) & Heart & 78 & Osaka University, Osaka, Japan & MOS 6 & 72 \\
\hline IPA & Lung & 53 & University of Amsterdam, Amsterdam, the Netherlands & CP 32 & 73 \\
\hline MPM & Lung & 39 & University of Bari Aldo Moro, Bari, Italy & $\mathrm{CP} 32$ & 74 \\
\hline Pneumonia & Lung & 400 & $\begin{array}{l}\text { Department of Anesthesia, University of Pennsylvania, } \\
\text { Philadelphia, PA, USA }\end{array}$ & BS & 75 \\
\hline \multirow[t]{3}{*}{ TB } & Lung & 46 & Cranfield University, Silsoe, Bedfordshire, UK & $\mathrm{CP} \mid 4$ & 76 \\
\hline & & 134 & Cranfield University, Silsoe, Bedfordshire, UK & $\mathrm{CP} 14$ & 77 \\
\hline & & 279 & $\begin{array}{l}\text { University of Santo Tomas, Manila, Philippines; } \\
\text { De La Salle University Hospital, Cavite, Philippines; } \\
\text { Homerton University Hospital, London, UK; } \\
\text { Hinduja Hospital, Mumbai, India }\end{array}$ & SAW I & 78 \\
\hline URTI & $\begin{array}{l}\text { Respiratory } \\
\text { tract }\end{array}$ & NS & $\begin{array}{l}\text { University of Pennsylvania Medical Center, } \\
\text { Philadelphia, PA, USA }\end{array}$ & CP 32 & 79 \\
\hline \multirow[t]{3}{*}{ VAP } & Lung & 25 & University of Pennsylvania, Philadelphia, PA, USA & CP 32 & 80 \\
\hline & & 38 & University of Pennsylvania, Philadelphia, PA, USA & CP 32 & 75 \\
\hline & & 44 & University of Pennsylvania, Philadelphia, PA, USA & CP 32 & 81 \\
\hline
\end{tabular}

Note: Adapted from Wilson AD. Advances in electronic-nose technologies for the detection of volatile biomarker metabolites in the human breath. Metabolites. 20I5;5: 140-163, ${ }^{35}$ originally published in the MDPI open access journal Metabolites.

Abbreviations: MC, Medical Center; ARDS, acute respiratory distress syndrome; COPD, chronic obstructive pulmonary disease; IPA, invasive pulmonary aspergillosis; MPM, malignant pleural mesothelioma; TB, tuberculosis; URTI, upper respiratory tract infections; VAP, ventilator-associated pneumonia; NS, not specified; BS, biosensor (experimental technology); CM, calorimetric; CP, conducting polymer; MOS, metal oxide semiconductor; QMB, quartz microbalance; SAW, surface acoustic wave.

reported. Moreover, VOC patterns from CF patients with chronic Pseudomonas aeruginosa infection differed significantly from those obtained from nonchronically infected CF patients.

Bos et $\mathrm{al}^{85}$ diagnosed ARDS in ventilated intensive care patients based on pulmonary injury and edema, inflammation, and Cyranose 320 e-nose analysis of VOC patterns within 24 hours of admission. Cases of ARDS were classified as "mild", "moderate", or "severe" according to the Berlin definition. The e-nose, trained using sparse-partial least square logistic regression, provided sensitivity results of $91 \%$ and specificity of $62 \%$ for discriminations between moderate and severe ARDS, confirming the results by temporal external validation. The Cyranose 320 e-nose provided discrimination between patients with ARDS, pneumonia, and cardiac pulmonary edema with only moderately accurate diagnostic results, although breathprints of patients with pneumonia and cardiac pulmonary edema were differentiated at greater accuracy than patients with ARDS.

Di Natale et a ${ }^{65}$ demonstrated that the composition of the breath of patients with lung cancer contains VOCs, mainly alkanes and aromatic compounds, which could be used to detect the disease. They used a QMB e-nose with eight sensors in the sensor array to screen patients for cancer by analysis of headspace composition in expired air. The QMB e-nose sensors showed good sensitivity to these possible lung cancer biomarkers in breath. They used partial least squaresdiscriminant analysis to find $100 \%$ of lung cancer-affected 
patients and $94 \%$ of reference samples were correctly classified. Among postsurgery patients, $44 \%$ of individuals in this category were correctly classified, while the remaining other samples were classified as healthy references. The alteration of breath composition induced by the presence of lung cancer was enough to allow a complete identification of the sample of diseased individuals. The results showed the effective capabilities of the QMB e-nose instrument to detect early stages of the disease for early cancer diagnosis.

\section{Emerging e-nose technologies}

Clinical diagnosticians often do diagnoses and classification of diseases based on information collected from several sources of physiological sensor signals. ${ }^{86}$ Likewise, the utilization of several sensing tools or machines, created by the fusion of two or more technologies, or through multiple sensor-signal fusions, is valuable to provide more robust and reliable determinations and diagnostic decisions in clinical cases. The analytical capabilities and types of commercially available combined-technology e-nose instruments were reviewed previously. ${ }^{8}$ New-generation e-nose instruments have been developed that have both breath-profiling capabilities as well as chemical analysis capabilities so that the composition of breathprints can be determined for identification of possible disease biomarkers. The Heracles II e-nose manufactured by AlphaMos (Toulouse, France) has been used in several clinical trials to assess the diagnostic capabilities to detect specific diseases. Although this instrument is not strictly classified as a traditional e-nose because it does not contain a cross-reactive multisensor array, it provides outputs from a dual-column gas chromatograph with flame ionization detector that consists of not only gas chromatography chemical data, but also e-nose-type vector data similar to smellprints produced by traditional e-nose instruments. Other commercially available combined-technology e-nose instruments of this type include calorimetric or catalytic bead, MOS, QMB, and SAW e-nose instrument types with added electron capture detector, ion mobility spectrometer, photoionization detector, mass spectrometer, $\mathrm{CO}_{2}, \mathrm{O}_{2}$, thermistor, and humidity sensors. ${ }^{8}$

A recent trend in clinical practice has been the strong shift toward POCT diagnostics to allow the very rapid diagnosis and treatment of patients. This new approach, referred to as paced or accelerated clinical decision-making, reduces the timescales of the diagnostic process through the elimination of expensive and time-consuming laboratory tests ${ }^{87}$ To achieve a prompt diagnosis and quick treatment, new portable e-nose devices are being developed that provide fast, simple, safe, and reliable clinical tests with improved sensor sensitivities, response times, low-power consumption, and miniaturization capabilities. One of these new e-nose technology types is complementary MOS cell devices that consist of microcell capacitance MOS sensors, normally attached to patient tissues, which monitor cellular responses and the presence of chemical agents. These devices may be used to test a variety of patient sample sources in the blood or plasma/serum, urine, bodily fluids, feces, and tissue samples ${ }^{88}$ Some disadvantages of using complementary MOS devices which currently limit extensive clinical applications have been difficulties with biocompatibility, contamination, and the complex packaging required to maintain functionality. ${ }^{89}$

Electrochemical biosensors (ECBs) are another technology group that offer fast, sensitive, and selective analysis of blood gases and chemicals, $\mathrm{pH}$, electrolytes, metabolites, DNA, and antibodies for spot and continuous testing (monitoring) of patients in hospital or clinical settings. ${ }^{90,91}$ Beyond bloodchemistry monitoring, the range of potential ECB applications in clinical diagnostics includes the detection of autoimmune diseases, cancer, cardiac biomarkers, infectious diseases, and genome analysis. ${ }^{92}$ Since the first ECB device was invented in 1962, consisting of an amperometric glucose oxidase enzyme electrode to measure dissolved oxygen, the performance and utility of ECBs have improved significantly with higher sensitivity, selectivity, and long-term stability. ECB devices are categorized based on the type of analyte or sensor design (measurement type) used in manufacturing. These sensors may operate on the basis of amperometric, conductometric, impedimetric, or potentiometric measurement principles for the sensing process. ECBs may be implanted subcutaneously or intravascularly depending on the monitoring task. One of the most important areas of ECB sensor application is in the continuous monitoring of blood glucose levels for the management of diabetes. Implantable glucose sensors provide continuous data of serum glucose levels without the need for blood withdrawal. Glucose sensors can be coupled with portable insulin-delivery devices that effectively function as an artificial endocrine pancreas to regulate insulin delivery in response to changes in blood glucose levels. In a similar application, Lai et $\mathrm{al}^{93}$ developed an implantable aptamer-based sensor to detect platelet-derived growth factor in blood serum at picomolar levels. The application of nanomaterials, such as carbon nanotubes used as electrode materials for electrochemical sensing, recently has become very popular due to their excellent properties of conductivity, unique structural and catalytic properties, high loading of biocatalysts, good stability, excellent penetrability, and miniaturization capabilities. ${ }^{91}$ Some limitations of certain electrochemical sensors include active interferences in the 
sample, weak long-term stability, and negative effects on cellular electron-transfer pathways. ${ }^{91}$

The adoption of plasmodic nanomaterials in optical (spectroscopic) sensors has offered the new potential for detecting, analyzing, and monitoring human physiological conditions and biochemical interactions at the single-molecule level using single nanoparticle-based surface plasmon resonance (SPR) biosensors. SPR oscillations of conduction-band electrons occur when light interacts with certain metals at the surface of the metal-dielectric interface of SPR biosensors. When a single-molecule analyte (chemical species) binds to the specific ligand of the metal film, interfacial architectural changes occur causing surface plasmons to be excited when exposed to a beam of light at a certain angle of incidence. ${ }^{94}$ The dielectric properties of the metal and surrounding material determine the optical properties of the plasmonic structures. The frequency and strength of these resonances depend on the size and shape of the metallic nanostructures.

SPR optical biosensor technologies have been proven to be among the most powerful technologies for determining specificity, affinity, and kinetic parameters during the binding of macromolecules in many bond types involved in biomolecular interactions. ${ }^{95}$ The bond types of macromolecular binding that can be detected by optical measures (eg, refractive index changes) include protein-protein, ${ }^{96,97}$ protein-DNA, ${ }^{98,99}$ enzyme-substrate, ${ }^{100,101}$ receptor-drug, ${ }^{102,103}$ lipid-protein, ${ }^{104,105}$ protein-polysaccharide, ${ }^{106}$ and host cell-virus, ${ }^{107-109}$ interactions. In order for analyte species to be detected, they must first be captured and immobilized on the surface of the sensor by analyte-specific capturing agents (ligands) such as antibodies, enzymes, peptides, or DNA strands. The careful choosing of appropriate and effective capturing agents is among the biggest challenges in applying SPR biosensors to POCT clinical diagnostics. Nonspecific binding of nontarget biomolecules can significantly interfere with the specificity and effective operation of SPR biosensors. ${ }^{110}$ In particular, the formation of a protein-corona around metal nanoparticles due to nonspecific binding in the cellular environment can cause spectral shifts, precluding detection of the intended specific target analyte. ${ }^{110,111}$

Plasmonic nanoparticles currently are utilized in clinical diagnostic tests for the detection of important biomarkers of diseases such as cancer and HIV, and various adverse physiological conditions and disorders associated with specific metabolites or chemical species. ${ }^{112}$ Chen et al ${ }^{94}$ developed an SPR biosensor for the detection of fetal fibronectin, a glycoprotein present in the extracellular matrix of amniotic membranes, which was found to be a powerful biomarker for predicting the risk of preterm births in pregnant women between 22 and 34 weeks of gestation. The detection range of the calibration curve for fibronectin quantitative measurements was $0.5-100 \mathrm{ng} / \mathrm{mL}$ and concentrations above the cutoff value of $50 \mathrm{ng} / \mathrm{mL}$ level were indicative of a significantly higher probability of preterm births. This SPR-based biosensor was considered a good alternative to the conventional enzyme-linked immunosorbent assay test because it allowed an earlier and more accurate diagnosis of preterm labor. Thus, early treatment of patients was possible by administering tocolytic therapy or steroids for fetal lung maturity and use of tertiary medical facilities for better prenatal care to decrease the incidence of perinatal morbidity and mortality. Many other potential applications of SPR biosensors are possible in the fields of bioengineering, biomedical, disease diagnostics, drug development, genomics, metabolomics, and proteomics as well as environmental and industrial areas. SPR nanoscale sensors will likely be further developed among the next-generation of biosensors for use in biological applications, including clinical medicine, because of their potential for detecting specific biomarkers of disease. SPR-based biosensors are capable of real-time quantitative chemical measurements (monitoring) of specific molecules. ${ }^{113}$ Single-molecule detection can also be achieved by a wide variety of other methods using nanoscale transistors made from carbon nanotubes, ${ }^{114-122} \mathrm{CP},{ }^{123-128}$ optical traps, ${ }^{129,130}$ and fluorescence-based methods. ${ }^{131}$

\section{Conclusion}

The widespread adoption of new sensor technologies across most fields of medicine represents a key test in the evolution of many diagnostic tools and procedures used in the clinical setting. ${ }^{132}$ E-nose devices currently are at the cusp of significant breakthroughs in widespread applications within the medical industry, and in particular, clinical medicine. These noninvasive gas-sensing devices potentially offer many advantages over conventional technologies currently used for disease diagnoses such as mammograms, colonoscopies, tissue biopsies, and other invasive procedures that cause unnecessary pain, discomfort, and long-analysis times for obtaining useful diagnostic results needed for decisionmaking by clinical physicians.

E-nose instruments comprise an array of different gassensitive technologies, although certain chemical-analysis instruments such as mass spectrometer, ion mobility spectrometer, selected ion flow tube mass spectrometers, infrared spectrometers, and gas chromatography-based devices are sometimes referred to as e-noses. ${ }^{35}$ However, the strict classic 
definition of an e-nose refers to instruments containing a cross-reactive sensor array that are collectively sensitive to the totality of VOCs present in a gaseous analyte mixture, rather than limited sensitivity to specific types of VOCs. Thus, individual sensors in the e-nose sensor array are globally sensitive to many of the compounds in a complex gaseous mixtures and each chemical is detected to varying degrees by more than one sensor, if not all sensors within the array. Nevertheless, e-nose devices may be specifically trained to recognize individual chemical compounds when in pure form or in simple gas sample mixtures. Some recent improvements in e-nose technologies are beginning to include chemical-identification capabilities to produce sophisticated combined-technology e-nose devices that are capable of both pattern recognition of complex gaseous samples (such as the human breath) as well as identifying individual compounds present in these complex gaseous samples.

There are some limitations of e-nose instruments that must be overcome before they may be used in certain medical applications. For example, e-noses are capable of detecting nonodorant gases such as carbon dioxide and various lowmolecular-weight hydrocarbons, but e-nose sensors often are insensitive to some substances detectable by the human nose, are affected by the presence of water vapor in sample analytes (particularly breath samples), can be inactivated (overloaded or poisoned) by certain highly polar compounds, and are generally nonspecific in sensitivity, although individual sensors may be specific to certain classes of VOCs. ${ }^{8,133-138}$ Due to poor specificity to individual volatiles, e-nose sensor arrays generally are not particularly suitable for identifying individual compounds present in complex gaseous mixtures such as in the human breath. ${ }^{43}$

Another key limitation of e-nose instruments is the absence of standardized methods for collection of VOC samples, and the particular e-nose devices and methods used to generate smellprints. Previously, expiratory flow rate, breath-holding capacity, and anatomic dead space were studied to determine if the method of exhaled breath sample collection from lung cancer patients and controls affected results. ${ }^{132}$ Differences in VOC pattern results were obtained from two different sampling methodologies, particularly in the control group. ${ }^{139}$ The interpretation of VOC patterns requires various statistical analysis and software applications, which is an important barrier that e-nose technologies must overcome to be fully embraced in clinical practice. More large-scale studies are needed to validate e-nose results and methods for various commercial e-nose devices to prove reproducibility of results between intra- and interlaboratory sample measurements. New prospective studies, including population-based screening for respiratory diseases, are key to determining the potential applicability of e-noses in daily clinical activity. ${ }^{132}$ The need for standardization of sample collection and analysis is the main issue concerning breath analysis, blocking the introduction of breath tests into clinical practice.

Breath analysis is a promising, recent new field in clinical medicine with great potential for noninvasive diagnosis of a number of human diseases throughout the body, not just respiratory diseases, due to the mobility of abnormal diseaseassociated VOCs within the human circulatory system and release from the body in EB air. ${ }^{11,35} \mathrm{E}$-nose instruments can play an effective part in breath analysis by effective determinations of VOC mixture types and relative molar concentrations of VOCs in the breath, which are defined by precise breathprint patterns using pattern recognition algorithms. E-nose instruments provide analytical techniques with high sensitivity, good precision (reproducibility), short response time, rapid sensor recovery, and relatively low detection limits, which are desirable characteristics for the detection and characterization of VOC mixtures present in the human breath. Breath fingerprinting along with chemical analyses of breath constituents (metabolomics) provide indications of specific clinical physiological health status and usually relies on the use of multivariate statistics methods with powerful built-in algorithms.

Advanced sampling procedures, such as solid-phase and needle trap microextraction, coupled with modern analytical technologies (proton transfer reaction mass spectrometry, selected ion flow tube mass spectrometry, ion mobility spectrometry, and e-noses) allow the characterization of EB composition to an unprecedented level. ${ }^{140} \mathrm{~EB}$ analysis requires proper statistical analysis and interpretation of large and heterogeneous datasets. Currently, there is no standard statistical protocol yet available that may be used for EB data analysis toward discovery of biomarkers for use in a typical clinical setup. Nevertheless, EB analysis has immense potential toward development of biomarkers for early disease diagnosis. ${ }^{14}$

E-nose devices also provide means for double checking and confirming a patient's identity as a means to assure that physician-recommended treatments and procedures (to be received by an individual patient) are meant for the specific patient intended, and confirmed before corrective treatments, such as surgeries and drug applications, are administered to the patient. ${ }^{6,35,142-144}$ Patient identity crosscheck procedures are essential for hospitals and clinics to avoid mistakes in 
patient treatment procedures that can lead to malpractice lawsuits and losses in public confidence in the effectiveness and competence of human health institutions. Rapid direct determinations of patient identity provides more reliable confirmations than conventional methods that rely on patient labels, bar-code technologies, and personnel judgments. ${ }^{145-147}$

There are great expectations for a large diversity of potential future applications of e-nose devices for POCT and diagnosis of various human diseases in hospitals and the clinical setting. These instruments are relatively simple, noninvasive, and transportable tools that potentially offer quick access to reliable clinical test results. E-nose instruments, comprising a wide diversity of gas-detection principals and mechanisms, represent compelling technologies for medical research and clinical applications. The potential capability of e-nose instruments to detect many diseases at early stages of development (by VOC pattern recognition) provides powerful tools for prescreening of patients during routine prophylactic clinical exams and allows early and more effective treatment of diseases usually with greatly improved prognoses. E-noses may also play a role in offering a more effective, personalized approach to disease detection and therapy in the future, particularly when used in combination with genetic screenings of patients for predispositions to specific diseases. E-nose methodologies of various types are relatively new to the clinical setting, but none is currently globally accepted. ${ }^{43}$ Thus, more research is needed to further evaluate and standardize e-nose devices and methods for clinical practice and medical research.

\section{Acknowledgment}

The author appreciates the help of Charisse Oberle for assistance in proofreading the manuscript, assembling literature references, and checking citation formatting.

\section{Disclosure}

The author reports no conflicts of interest in this work.

\section{References}

1. Lourenço C, Turner C. Breath analysis in disease diagnosis: methodological considerations and applications. Metabolites. 2014;4:465-498.

2. Smith D, Španěl P. Application of ion chemistry and the SIFT technique to the quantitative analysis of trace gases in air and on breath. Int Rev Phys Chem. 1996;15:231-271.

3. Jordan A, Hansel A, Holzinger R, Lindinger W. Acetonitrile and benzene in the breath of smokers and non-smokers investigated by proton transfer reaction mass spectrometry (PTR-MS). Int J Mass Spectrom. 1995;148: L1-L3.

4. Phillips M, Gleeson K, Hughes J, et al. Volatile organic compounds in breath as markers of lung cancer: a cross-sectional study. Lancet. 1999;353:1930-1933.
5. Lacy Costello B, Amann A, Al-Kateb H, et al. A review of the volatiles from the healthy human body. J Breath Res. 2014;8:1-29.

6. Wilson $\mathrm{AD}$, Baietto M. Advances in electronic-nose technologies developed for biomedical applications. Sensors. 2011;11: $1105-1176$

7. Wilson AD. Future applications of electronic-nose technologies in healthcare and biomedicine. In: Akyar I, editor. Wide Spectra of Quality Control. Rijeka: InTech; 2011:267-290.

8. Wilson AD, Baietto M. Applications and advances in electronic-nose technologies. Sensors. 2009;9:5099-5148.

9. Wilson AD, Lester DG, Oberle CS. Development of conductive polymer analysis for the rapid detection and identification of phytopathogenic microbes. Phytopathology. 2004;94:419-431.

10. Kybert NJ, Egan L, Waldman RZ, et al. Analysis of sweat simulant mixtures using multiplexed arrays of DNA-carbon nanotube vapor sensors. J Forensic Sci Criminol. 2014;1:S102.

11. Wilson AD. Electronic-nose applications in forensic science and for analysis of volatile biomarkers in the human breath. J Forensic Sci Criminol. 2014;1:S103.

12. Casey V, Cleary J, Arcy GD, McMonagle JB. Calorimetric combustible gas sensor based on a planar thermopile array: fabrication, characterisation, and gas response. Sensor Actuat B-Chem, 2013;96: 114-123.

13. Kirchner P, Oberländer J, Friedrich P, et al. Realisation of a calorimetric gas sensor on polyimide foil for applications in aseptic food industry. Sensor Actuat B-Chem. 2012;170:60-66.

14. Ervina MH, Millera BS, Hanrahana B, Mailly B, Palacios T. A comparison of single-wall carbon nanotube electrochemical capacitor electrode fabrication methods. Electrochim Acta. 2012;65:37-43.

15. Kang H, Lim S, Park N, Chun KY, Baik S. Improving the sensitivity of carbon nanotube sensors by benzene functionalization. Sensor Actuat B-Chem. 2010;147:316-321.

16. Zheng J, Zhang QQ, He XC, Gao MJ, Ma XF, Li G. Nanocomposites of carbon nanotube $(\mathrm{CNTs}) / \mathrm{CuO}$ with high sensitivity to organic volatiles at room temperature. Proc Engin. 2012;36:235-245.

17. Hannon A, Lu Y, Li J, Meyyappan M. Room temperature carbon nanotube based sensor for carbon monoxide detection. J Sens Sens Syst. 2014;3:349-354.

18. Lee J, Kim WD, Lim H. Facile fabrication of conducting polymer nanowire based field effect transistor with controlled shape and position. Microelectron Engin. 2012;98:382-385.

19. Vaschetto ME, Monkman AP, Springborg M. First-principle studies of some conducting polymers: PPP, PPy, PPV, PPyV, and PANI. $J$ Mol Struct. 1999;468:181-191.

20. Luo C, Chakraborty A. Effects of dimensions on the sensitivity of a conducting polymer microwire sensor. Microelectron J. 2009;40: 912-920.

21. Zohora SE, Khan AM, Srivastava AK, Hundewale N. Chemical sensors employed in electronic noses: a review. Int J Soft Comput Engin. 2013;3: 2231-2307.

22. Feng W, Hettiarachchi R, Sato S, et al. Advantages of silicon nanowire metal-oxide-semiconductor field-effect transistors over planar ones in noise properties. Jpn J Appl Phys. 2012;51:04DC06.

23. Oprea A, Bârsan N, Weimar U. Characterization of granular metal oxide semiconductor gas sensitive layers by using Hall effect based approaches. J Phys D: Appl Phys. 2007;40:7217-7237.

24. Albert KJ, Lewis NS, Cross reactive chemical sensor arrays. Chem Rev. 2000;100:2595-2626.

25. Gabriele ML, Wollstein G, Ishikawa H, et al. Three dimensional optical coherence tomography imaging: advantages and advances. Progr Retin Eye Res. 2010;29:556-579.

26. Blumentritt M, Melhorn K, Flachsbarth J, Kroener M, Kowalsky W, Johannes HH. A novel fabrication method of fiber-optical planar transmission sensors for monitoring $\mathrm{pH}$ in concrete structures. Sensor Actuat B-Chem. 2008;131:504-508.

27. Walt DR, Dikenson T, White J, et al. Optical sensor arrays for odor recognition. Biosens Bioelectron. 1998;13:697-699. 
28. Smith AL, Shirazi HM. Principles of quartz crystal microbalance/ heat conduction calorimetry: measurement of the sorption enthalpy of hydrogen in palladium. Thermochim Acta. 2005;432:202-211.

29. Pejcic B, Crookea E, Doherty CM, et al. The impact of water and hydrocarbon concentration on the sensitivity of a polymer-based quartz crystal microbalance sensor for organic compounds. Analyt Chim Acta. 2011;703:70-79.

30. Pejcic B, Barton C, Crooke E, Eadington P, Jee E, Ross A. Hydrocarbon sensing. Part 1: Some important aspects about sensitivity of a polymercoated quartz crystal microbalance in the aqueous phase. Sensor Actuat B-Chem. 2009;135:436-443.

31. Xiea G, Suna P, Yana X, Dua X, Jianga Y. Fabrication of methane gas sensor by layer-by-layer self-assembly of polyaniline/PdO ultrathin films on quartz crystal microbalance. Sensor Actuat B-Chem 2010;145:373-377.

32. Lai FD, Huang HM. Fabrication of high frequency and low-cost surfaceacoustic wave filters using near field phase shift photolithography. Microelectron Engin. 2006;83:1407-1409.

33. Krishnamoorthy S, Iliadis AA. Properties of high sensitivity $\mathrm{ZnO}$ surface acoustic wave sensors on $\mathrm{SiO}_{2} /(100)$ Si substrates. Solid-State Electron. 2008;52:1710-1716.

34. Fan L, Ge H, Zhang SY, Zhang H, Zhu J. Optimization of sensitivity induced by surface conductivity and adsorbed mass in surface acoustic wave gas sensors. Sensor Actuat B-Chem. 2012;161:114-123.

35. Wilson AD. Advances in electronic-nose technologies for the detection of volatile biomarker metabolites in the human breath. Metabolites. 2015;5:140-163.

36. Wilson AD. Diverse applications of electronic-nose technologies in agriculture and forestry. Sensors. 2013;13:2295-2348.

37. Bahadoran M, Noorden AFA, Chaudhary K, et al. Modeling and analysis of a microresonating biosensor for detection of Salmonella bacteria in human blood. Sensors. 2014;14:12885-12899.

38. Gikunoo E, Abera A, Woldesenbet E. A novel carbon nanofibers grown on glass microballoons immunosensor: a tool for early diagnosis of malaria. Sensors. 2014;14:14686-14699.

39. Phillips M, Beatty JD, Cataneo RN, et al. Rapid point-of-care breath test for biomarkers of breast cancer and abnormal mammograms. PLoS ONE. 2014;9:e90226.

40. de Meij TG, Larbi IB, van der Schee MP, et al. Electronic nose can discriminate colorectal carcinoma and advanced adenomas by fecal volatile biomarker analysis: proof of principle study. Int J Cancer. 2014;134: 1132-1138.

41. Yusuf N, Zakaria A, Omar MI, et al. In-vitro diagnosis of single and poly microbial species targeted for diabetic foot infection using e-nose technology. BMC Bioinformatics. 2015;16:158-169.

42. Bruno DL, Haroution A, Magda CC, Radu I. Smell, lung cancer, electronic nose and trained dogs. J Lung Pulm Respir Res. 2014;1(2):00011.

43. Montuschi, P Mores N, Trové A, Mondino C, Barnes PJ. The electronic nose in respiratory medicine. Respiration. 2013;85:72-84.

44. Chilo J, Horvath G, Lindblad T, Olsson R, Redeby J, Roeraade J. A flexible electronic nose for ovarian carcinoma diagnosis in real time. Proceedings of the Real Time Conference 16th IEEE-NPSS; May 10-15, 2009; Beijing, China. New York: IEEE; 2009.

45. Roine A, Veskimäe E, Tuokko A, et al. Detection of prostate cancer by an electronic nose: a proof of principle study. J Urol. 2014;192(1): 230-235.

46. Greulich T, Hattesohl A, Grabisch, A, et al. Detection of obstructive sleep apnoea by an electronic nose. Eur Respir J. 2013;42:145-155.

47. Roine A, Saviauk T, Kumpulainen P, et al. Rapid and accurate detection of urinary pathogens by mobile IMS-based electronic nose: a proof-ofprinciple study. PLoS ONE, 2014;9:e114279.

48. Tharsika T, Haseeb ASMA, Akbar SA, Sabri MFM, Hoong WY. Enhanced ethanol gas sensing properties of $\mathrm{SnO}_{2}$-core/ZnO-shell nanostructures. Sensors. 2014;14:14586-14600.

49. Voss A, Witt K, Kaschowitz T, et al. Detecting cannabis use on the human skin surface via an electronic nose system. Sensors. 2014;14: 13256-13272.
50. Zhao X, Cai B, Tang Q, Tong Y, Liu Y. One-dimensional nanostructure field-effect sensors for gas detection. Sensors. 2014;14: 13999-14020.

51. Essiet IO. Diagnosis of kidney failure by analysis of the concentration of ammonia in exhaled breath. J Emerg Trends Eng Appl Sci. 2013;4(6):859-862.

52. Wongchoosuk C, Lutz M, Kerdcharoen T. Detection and classification of human body odor using an electronic nose. Sensors. 2009;9: 7234-7249.

53. Clausen I, Glott T. Development of clinically relevant implantable pressure sensors: perspectives and challenges. Sensors. 2014;14: 17686-17702.

54. Rodríguez-Sevilla E, Ramírez-Silva M-T, Romero-Romo M, IbarraEscutia P, Palomar-Pardavé M. Electrochemical quantification of the antioxidant capacity of medicinal plants using biosensors. Sensors. 2014;14:14423-14439.

55. Alqasaimeh M, Heng LY, Ahmad M, Raj AS, Ling TL. A large response range reflectometric urea biosensor made from silica-gel nanoparticles. Sensors. 2014;14:13186-13209.

56. Ismaiel AA, Kheireddine M, Yusoff R. A new electrochemical sensor based on task-specific ionic liquids-modified palm shell activated carbon for the determination of mercury in water samples. Sensors. 2014;14: 13102-13113.

57. Haick H, Broza YY, Mochalski P, Ruzsanyi V, Amann A. Assessment, origin, and implementation of breath volatile cancer markers. Chem Soc Rev. 2014;43:1423-1449.

58. Smith D, Španěl P. The challenge of breath analysis for clinical diagnosis and therapeutic monitoring. Analyst. 2007;132:390-396.

59. Chapman EA, Thomas, PS, Stone E, Lewis, C, Yates, DH. A breath test for malignant mesothelioma using an electronic nose. Eur Respir J. 2012;40:448-454

60. Dragonieri S, Schot R, Mertens BJ, et al. An electronic nose in the discrimination of patients with asthma and controls. J Allergy Clin Immunol. 2007;120:856-862.

61. Montuschi P, Santonico M, Mondino C, et al. Diagnostic performance of an electronic nose, fractional exhaled nitric oxide, and lung function testing in asthma. Chest. 2010;137:790-796.

62. Fens N, Zwinderman AH, van der Schee MP, et al. Exhaled breath profiling enables discrimination of chronic obstructive pulmonary disease and asthma. Am J Respir Crit Care Med. 2009;180:1076-1082.

63. Fens N, Roldaan AC, van der Schee MP, et al. External validation of exhaled breath profiling using an electronic nose in the discrimination of asthma with fixed airways obstruction and chronic obstructive pulmonary disease. Clin Exp Allergy. 2011;41:1371-1378.

64. Timms C, Thomas PS, Yates DH. Detection of gastro-oesophageal reflux disease (GORD) in patients with obstructive lung disease using exhaled breath profiling. J Breath Res. 2012;6:016003.

65. Di Natale C, Macagnano A, Martinelli E, et al. Lung cancer identification by the analysis of breath by means of an array of non-selective gas sensors. Biosens Bioelectron. 2003;18:1209-1218.

66. Machado RF, Laskowski D, Deffenderfer O, et al. Detection of lung cancer by sensor array analyses of exhaled breath. Am J Respir Crit Care Med. 2005;171:1286-1291.

67. Mazzone PJ, Hammel J, Dweik R, et al. Diagnosis of lung cancer by the analysis of exhaled breath with a colorimetric sensor array. Thorax. 2007;62:565-568.

68. D’Amico A, Pennazza G, Santonico M, et al. An investigation on electronic nose diagnosis of lung cancer. Lung Cancer. 2010;68:170-176.

69. Mazzone PJ, Wang XF, Xu Y, et al. Exhaled breath analysis with a colorimetric sensor array for the identification and characterization of lung cancer. J Thorac Oncol. 2012;7:137-142.

70. Hattesohl AD, Jorres RA, Dressel H, et al. Discrimination between COPD patients with and without alpha 1-antitrypsin deficiency using an electronic nose. Respirology. 2011:16:1258-1264.

71. Dragonieri S, Annema JT, Schot R, et al. An electronic nose in the discrimination of patients with non-small cell lung cancer and COPD Lung Cancer. 2009;64:166-170. 
72. Tanaka $\mathrm{M}$, Anguri $\mathrm{H}$, Nonaka A, et al. Clinical assessment of oral malodor by the electronic nose system. J Dent Res. 2004;83:317-321.

73. de Heer K, van der Schee MP, Zwinderman K, et al. Invasive pulmonary aspergillosis in prolonged chemotherapy-induced neutropenia: a proof-of-principle study. J Clin Microbiol. 2013;51:1490-1495.

74. de Gennaro G, Dragonieri S, Longobardi F, et al. Chemical characterization of exhaled breath to differentiate between patients with malignant pleural mesothelioma from subjects with similar professional asbestos exposure. Anal Bioanal Chem. 2010;398:3043-3050.

75. Hanson CW III, Thaler ER. Electronic nose prediction of a clinical pneumonia score: biosensors and microbes. Anesthesiology. 2005;102: 63-68.

76. Pavlou A, Magan N, Jones J, Brown J, Klatser P, Turner A. Detection of Mycobacterium tuberculosis (TB) in vitro and in situ using an electronic nose in combination with a neural network system. Biosens Bioelectron. 2004;20:538-544.

77. Fend R, Kolk AHJ, Bessant C, Buijtels P, Klatser PR, Woodman AC. Prospects for clinical application of electronic-nose technology to early detection of Mycobacterium tuberculosis in culture and sputum. J Clin Microbiol. 2006;44:2039-2045.

78. Phillips M, Basa-Dalay V, Blais J, et al. Point-of-care breath test for biomarkers of active pulmonary tuberculosis. Tuberculosis. 2012;92: 314-320.

79. Lai SY, Deffenderfer OF, Hanson W, Phillips MP, Thaler ER. Identification of upper respiratory bacterial pathogens with the electronic nose. Laryngoscope. 2002;112:975-979.

80. Hockstein NG, Thaler ER, Torigian D, Miller WT Jr, Deffenderfer O, Hanson CW. Diagnosis of pneumonia with an electronic nose: correlation of vapor signature with chest computed tomography scan findings. Laryngoscope. 2004;114:1701-1705.

81. Hockstein NG, Thaler ER, Lin Y, Lee DD, Hanson CW. Correlation of pneumonia score with electronic nose signature: a prospective study. Ann Otol Rhinol Laryngol. 2005;114:504-508.

82. Baxter CG, Bishop P, Low SE, Baiden-Amissah K, Denning DW. Pulmonary aspergillosis: an alternative diagnosis to lung cancer after positive [18F]FDG positron emission tomography. Thorax. 2011;66: 638-640.

83. Gerritsen MG, Brinkman P, de Heer K, et al. Detection of invasive aspergillosis by an electronic nose platform: Preliminary data in a validation cohort. Eur Respir J. 2014;44:S58.

84. Joensen O, Paff T, Haarman EG, et al. Exhaled breath analysis using electronic nose in cystic fibrosis and primary ciliary dyskinesia patients with chronic pulmonary infections. PLoS ONE. 2014;9:e115584.

85. Bos LDJ, Schultz MJ, Sterk, PJ. Exhaled breath profiling for diagnosing acute respiratory distress syndrome. BMC Pulm Med. 2014;14:72.

86. Begum S, Barua S, Ahmed MU. Physiological sensor signals classification for healthcare using sensor data fusion and case-based reasoning. Sensors. 2014;14:11770-11785.

87. AdiguzelY, Kulah H. CMOS cell sensors for point-of-care diagnostics. Sensors. 2012;12:10042-10066.

88. von Lode P. Point-of-care immunotesting: approaching the analytical performance of central laboratory methods. Clin Biochem. 2005;38: 591-606.

89. Barrettino D. Design considerations and recent advances in CMOSbased microsystems for point-of-care clinical diagnostics. Proceedings of the IEEE International Symposium on Circuits and Systems; May 21-24, 2006; Island of Kos, Greece. New York: IEEE; 2006: 4359-4362.

90. Li CM, Dong H, Cao X, Luong JHT, Zhang X. Implantable electrochemical sensors for biomedical and clinical applications: progress, problems, and future possibilities. Curr Med Chem. 2007;14: $1-23$.

91. Wang Y, Xu H, Zhang J, Li G. Electrochemical sensors for clinic analysis. Sensors. 2008;8:2043-2081.

92. Bunyakul N, Baeumner AJ. Combining electrochemical sensors with miniaturized sample preparation for rapid detection in clinical samples. Sensors. 2015;15:547-564.
93. Lai RY, Plaxco KW, Heeger AJ. Aptamer-based electrochemical detection of picomolar platelet-derived growth factor directly in blood serum. Anal Chem. 2007:79:229-233.

94. Chen CY, Chang CC, Yu C, Lin CW. Clinical application of surface plasmon resonance-based biosensors for fetal fibronectin detection. Sensors. 2012;12:3879-3890.

95. Nguyen HH, Park J, Kang S, Kim N. Surface plasmon resonance: a versatile technique for biosensor applications. Sensors. 2015;15: 10481-10510.

96. Kim M, Park K, Jeong EJ, Shin YB, Chung BH. Surface plasmon resonance imaging analysis of protein-protein interactions using onchip-expressed capture protein. Anal Biochem. 2006;351:298-304.

97. Madeira A, Vikeved E, Nilsson A, Sjögren B, Andrén PE, Svenningsson P. Identification of protein-protein interactions by surface plasmon resonance followed by mass spectrometry. Curr Protoc Protein Sci. 2011;65:19.21.1-19.21.9.

98. Majka J, Speck C. Analysis of protein-DNA interactions using surface plasmon resonance. Adv Biochem Eng Biotechnol. 2007;104:13-36.

99. Teh HF, Peh WYX, Su X, Thomsen JS. Characterization of proteinDNA interactions using surface plasmon resonance spectroscopy with various assay schemes. Biochemistry. 2007;46:2127-2135.

100. Fong CC, Lai WP, Leung YC, Lo SCL, Wong MS, Yang M. Study of substrate-enzyme interaction between immobilized pyridoxamine and recombinant porcine pyridoxal kinase using surface plasmon resonance biosensor. Biochim Biophys Acta. 2002;1596:95-107.

101. Geitmann M, Danielson UH. Studies of substrate-induced conformational changes in human cytomegalovirus protease using optical biosensor technology. Anal Biochem. 2004;332:203-214.

102. Salamon Z, Cowell S, Varga E, Yamamura HI, Hruby VJ, Tollin G. Plasmon resonance studies of agonist/antagonist binding to the human delta-opioid receptor: new structural insights into receptor-ligand interactions. Biophys J. 2000;79:2463-2474.

103. Rich RL, Hoth LR, Geoghegan KF, et al. Kinetic analysis of estrogen receptor/ligand interactions. Proc Natl Acad Sci U S A. 2002;99: 8562-8567.

104. Baron OL, Pauron D, Antipolis S. Protein-lipid interaction analysis by surface plasmon resonance (SPR). Bio-Protocol. 2014;4:1-8.

105. Erb EM, Chen X, Allen S, et al. Characterization of the surfaces generated by liposome binding to the modified dextran matrix of a surface plasmon resonance sensor chip. Anal Biochem. 2000;280:29-35.

106. Beccati D, Halkes KM, Batema GD, et al. SPR studies of carbohydrateprotein interactions: signal enhancement of low-molecular-mass analytes by organoplatinum(II)-labeling. Chembiochem. 2005;6: 1196-1203.

107. Zhang H, Yang L, Zhou B, et al. Investigation of biological cellprotein interactions using SPR sensor through laser scanning confocal imaging-surface plasmon resonance system. Spectrochim Acta A Mol Biomol Spectrosc. 2014;121:381-386.

108. Besenicar M, Macek P, Lakey JH, Anderluh G. Surface plasmon resonance in protein-membrane interactions. Chem Phys Lipids. 2006;141:169-178.

109. Miyoshi H, Suehiro N, Tomoo K, et al. Binding analyses for the interaction between plant virus genome-linked protein $(\mathrm{VPg})$ and plant translational initiation factors. Biochimie. 2006;88:329-340.

110. Zhang J, Sun Y, Xu B, et al. A novel surface plasmon resonance biosensor based on graphene oxide decorated with gold nanorod-antibody conjugates for determination of transferrin. Biosens Bioelectron. 2013;45:230-236.

111. Cittadini M, Bersani M, Perrozzi F, Ottaviano L, Wlodarski W, Martucci A. Graphene oxide coupled with gold nanoparticles for localized surface plasmon resonance based gas sensor. Carbon N Y, 2014;69:452-459.

112. Wu L, Chu HS, Koh WS, Li EP. Highly sensitive graphene biosensors based on surface plasmon resonance. Opt Express. 2010;18: 14395-14400.

113. Sriram M, Zong K, Vivekchand SRC, Gooding JJ. Single nanoparticle plasmonic sensors. Sensors. 2015;15:25774-25792. 
114. Kruss S, Hilmer AJ, Zhang J, Reuel NF, Mu B, Strano MS. Carbon nanotubes as optical biomedical sensors. Adv Drug Deliv Rev. 2013;65:1933-1950.

115. Landry MP, Kruss S, Nelson JT, et al. Experimental tools to study molecular recognition within the nanoparticle corona. Sensors. 2014;14: 16196-16211.

116. Besteman K, Lee JO, Wiertz FGM, Heering HA, Dekker C. Enzymecoated carbon nanotubes as single-molecule biosensors. Nano Lett. 2003;3:727-730.

117. Tisch U, Haick H. Arrays of nanomaterial-based sensors for breath testing. In: Amann A, Smith D, editors. Volatile Biomarkers: NonInvasive Diagnosis in Physiology and Medicine. Amsterdam: Elsevier; 2013:301-323.

118. Barash O, Peled N, Hirsch FR, Haick H. Sniffing the unique "odor print” of non-small-cell lung cancer with gold nanoparticles. Small. 2009;5:2618-2624.

119. Bashouti MY, Sardashti K, Schmitt SW, et al. Oxide-free hybrid silicon nanowires: from fundamentals to applied nanotechnology. Progr Surface Sci. 2013;88:39-60.

120. Barash O, Peled N, Tisch U, Bunn Jr PA, Hirsch FR, Haick H. Classification of lung cancer histology by gold nanoparticle sensors. Nanomed Nanotech Biol Med. 2012;8:580-589.

121. Peng G, Hakim M, Broza YY, et al. Detection of lung, breast, colorectal, and prostate cancers from exhaled breath using a single array of nanosensors. Br J Cancer. 2010;103:542-551.

122. Tisch U, Billan S, Ilouze M, Phillips M, Peled N, Haick, H. Volatile organic compounds in the exhaled breath as biomarkers for the early detection and screening of lung cancer. CML Lung Cancer. 2012;5: 107-117.

123. Patolsky F, Zheng G, Lieber CM. Fabrication of silicon nanowire devices for ultrasensitive, label-free, real-time detection of biological and chemical species. Nature Protoc. 2006;1:1711-1724.

124. Zheng G, Lieber CM. Nanowire biosensors for label-free, realtime, ultrasensitive protein detection. Methods Mol Biol. 2011;790: 223-237.

125. Lieber CM. Semiconductor nanowires: a platform for nanoscience and nanotechnology. MRS Bull. 2011;36:1052-1063.

126. Mulchandani A, Myung NV. Conducting polymer nanowires-based label-free biosensors. Curr Opin Biotech. 2011;22:502-508.

127. Yoon H, Ko S, Jang J. Field-effect-transistor sensor based on enzymefunctionalized polypyrrole nanotubes for glucose detection. $J$ Phys Chem. 2008;112:9992-9997.

128. Arter JA, Taggart DK, McIntire TM, Penner RM, Weiss GA. Virus-PEDOT nanowires for biosensing. Nano Lett. 2010;10: 4858-4862.

129. Kotnala A, Gordon R. Quantification of high-efficiency trapping of nanoparticles in a double nanohole optical tweezer. Nano Lett. 2014; 14:853-856.
130. Pang Y, Gordon R. Optical trapping of a single protein. Nano Lett. 2012;12:402-406.

131. Joo C, Balci H, Ishitsuka Y, Buranachai C, Ha T. Advances in singlemolecule fluorescence methods for molecular biology. Annu Rev Biochem. 2008;77:51-76.

132. Fiorentino F, Valera JL, Merino JL, Cosio BG. The electronic nose arises into the 21st century. EMJ Respir. 2015;3:12-17.

133. Röck F, Barsan N, Weimar U. Electronic nose: current status and future trends. Chem Rev. 2008;108:705-711.

134. Turner A, Magan N. Electronic noses and disease diagnostics. Nat Rev Microbiol. 2004;2:161-166.

135. Baldwin EA, Bai J, Plotto A, Dea S. Electronic noses and tongues: applications for the food and pharmaceutical industries. Sensors. 2011;11:4744-4766.

136. Deisingh AK, Stone DC, Thompson M. Applications of electronic noses and tongues in food analysis. Int J Food Sci Technol. 2004;39:587-604.

137. Buck L, Axel R. A novel multigene family may encode odorant receptors: a molecular basis for odor recognition. Cell. 1991;65:175-187.

138. D’Amico A, Di Natale C, Paolesse R, et al. Olfactory systems for medical applications. Sensor Actuat B-Chem. 2008;130:458-465.

139. Bikov A, Hernadi M, Korosi BZ, et al. Expiratory flow rate, breath hold and anatomic dead space influence electronic nose ability to detect lung cancer. BMC Pulm Med. 2014;14:202.

140. Pereira J, Porto-Figueira P, Cavaco C, et al. Breath analysis as a potential and non-invasive frontier in disease diagnosis: an overview. Metabolites. 2014;5:3-55.

141. Scarlata S, Pennazza G, Santonico M, Pedone C. Exhaled breath analysis by electronic nose in respiratory diseases. Expert Rev $\mathrm{Mol}$ Diagn. 2015;15:933-956.

142. Yang MT, Huang SY. Appearance-based multimodal human tracking and identification for healthcare in the digital home. Sensors. 2014;14:14253-14277.

143. Cho SH. Unravel the secret of olfaction. Hanyang Med Rev. 2014;34: 97-99.

144. Li S. Recent developments in human odor detection technologies. J Forensic Sci Criminol. 2014;1:S104.

145. Helmons PJ, Wargel LN, Daniels CE. Effect of bar-code-assisted medication administration on medication administration errors and accuracy in multiple patient care areas. Am J Health Syst Pharm. 2009;66:1202-1210.

146. Henneman EA, Roche JP, Fisher DL, et al. Error identification and recovery by student nurses using human patient simulation: opportunity to improve patient safety. Appl Nursing Res. 2010;23:11-21.

147. Wilson AD. Advanced methods for teaching electronic-nose technologies to diagnosticians and clinical laboratory technicians. Proc Soc Behav Sci. 2012;46:4544-4554.
Nanobiosensors in Disease Diagnosis

\section{Publish your work in this journal}

Nanobiosensors in Disease Diagnosis is an international, peer-reviewed, open access journal publishing original research, reports, reviews and commentaries including but not confined to: Diagnosis of diseases including cancer, cardiovascular, infectious diseases; Molecular modeling in diagnosis; Enzyme and membrane technologies; and quantum

\section{Dovepress}

dot fluorescence technologies for monitoring toxins and pathogens. The manuscript management system is completely online and includes a very quick and fair peer-review system, which is all easy to use. Visit http://www.dovepress.com/testimonials.php to read real quotes from published authors. 